\title{
"None of the Kids Are Allowed to Eat Junk at the Pool": Discourses of 'Optimal' Nutrition in Competitive Youth Swimming and the Impact on Athlete Welfare
}

\author{
Melanie Lang, Edge Hill University, UK
}

\begin{abstract}
In modern competitive sport, athletic success is posited as a result of more than simply being physically fit (Johns and Johns, 2000; Romana, 2010). Rather, understandings of the 'best' way to physically prepare as an athlete, underpinned by bio-scientific discourses of performance that emphasize rationalistic concepts of productivity, efficiency and conformity, have come to attribute certain meanings to athletes' preparation, including that they must comply with strict training regimes and controlled lifestyles to achieve success (Lang, 2010; Potrac et al., 2000). Within this, ensuring 'appropriate' nutritional intake is considered crucial. However, knowledge of coaches' discourses in relation to athlete development and how they enact this in their practice is under researched (Jones, Glintmeyer and McKenzie, 2005), particularly in relation to coaches' work with child athletes and in relation to coaches' understandings of discourses of athlete nutrition. This paper aims to contribute to these knowledge gaps. The paper reports the findings from an ethnographic study into coaches' understanding of good practice when working with competitive youth swimmers and how they enact this in their practice. The study comprised an ethnography of three competitive youth swimming clubs at different levels of the performance spectrum. One of the key findings from the study was that coaches considered it good practice to educate youth athletes about what they referred to as 'good' or 'optimal' nutrition and consequently, particularly among coaches at the elite level, they enforced strict dietary rules to achieve this. The consequences of exposing youth athletes to such practices are discussed in relation to the health and wellbeing of (child) athletes.
\end{abstract}

Keywords: Youth Sport, Swimming, Sports Nutrition, Performance Discourse

\section{Performance Discourses in Modern Sport}

$\mathrm{M}$ odern competitive sport is underpinned by discourses of performance that are based on scientific functionalism (Cassidy, Jones and Potrac, 2009; Coakley, 1992; Johns and Johns, 2002). Consequently, the focus is on the pursuit of performance and, concomitantly, how performance can be enhanced (Tinning, 1997). In this climate where success is centralised, the key consideration becomes how performance can be improved, and in recent decades sports science increasingly has been regarded as one method of obtaining such improvement. Ensuring athletes eat an 'appropriate' diet has been identified as central to constructions of appropriate physical preparation for athletes (Bridel, 2013; Johns and Johns, 2000; Lee and McDonald, 2010), particularly since the emergence of sports nutrition as a distinct discipline in the 1980s following collaborations between exercise physiologists and nutritionists (Dunford, 2010). Today, what is often referred to as 'optimal nutrition' (see English Institute of Sport, no date; United States (US) Anti-Doping Agency, 2010) is believed to positively influence performance, immune system health, injury and recovery rates, and growth and maturation levels (Meyer, O'Connor and Shirreffs, 2007), particularly in youth athletes who are "faced with the challenge of meeting nutrition requirements for growth and development, as well as sport performance" (Gibson et al., 2011, 507). This has led numerous sports organizations, including the American College of Sports Medicine (Rodriguez, DiMarco and Langley, 2001), the International Olympic Committee (IOC) (2010, 2012), the US Anti-Doping Agency (2010) and the United Kingdom's high-performance agency UK Sport (no date), to note the importance of what they refer to as 'optimal' nutrition for athletic performance 
Nutrition plays a critical role in athletic performance, and athletes, coaches, and parents need to realize that making wise food choices can increase the chances of optimal athletic performance. (US Anti-Doping Agency, 2010, 29)

In line with the dominance of performance discourses in modern sport, coach qualification and education courses often focus primarily on the physical development of athletes, providing coaches with physiological knowledge such as the mechanics of the relevant sport and ways of improving athletes' strength, conditioning and nutrition (Cassidy, Jones and Potrac, 2009; Tinning, 1997). Discourses of 'optimal' nutrition and weight management to enhance performance also commonly feature in coach qualification and education courses. For example in swimming, which is the context of the study reported here, the Amateur Swimming Association (ASA) Level 2 Certificate in Coaching Swimming contains an assessed module called Understanding Basic Nutrition and Hydration Principles for Sports Performance, where learners study the principles of "good nutrition" as it relates to sports performance, and "how best to achieve optimum nutrition and hydration levels before, during and after training and competition" (ASA, 2013, 12). Similarly, the Level 3 Certificate in Coaching Swimming qualification contains a module on Understanding How to Provide Participant(s) with Nutritional Advice within Sport-Specific Annual Coaching Programmes, where coaches study "the principles of sport nutrition" and are assessed on being able to "describe optimal nutrition and hydration strategies" (ASA, 2012, 11).

Within this discourse, the athletic body is constructed as a biophysical object - one that can be 'improved' by, in part, ensuring 'optimal' nutritional intake (Pronger, 2002). To this end, a simplistic but logically appealing "engineering input-output model" of nutrition (Spoel, Harris and Henwood, 2012, 4) often underpins advice provided to athletes, wherein athletes are constructed as machines (often Ferraris or other high-performance sports cars) and the food athletes eat referred to as 'energy' or 'fuel'. The analogy goes that athletes, like cars, need to get enough energy/fuel but not too much - to run their engine. Overfilling the tank, it is often warned, can result in athletes being overweight or obese, which is assumed to be negative for athletic performance (Anderson et al., 2011; Rodriguez, DiMarco and Langley, 2001). Meanwhile, energy deficits can lead to a range of ailments, increased likelihood of injury, and poor performance (Meyer, O'Connor and Shirreffs, 2007). For example:

Optimal nutrition is an integral part of peak performance while an inadequate diet and lack of fuel can limit an athlete's potential for maximum performance. (US Anti-Doping Agency, 2010, 1, emphasis added)

A diet that provides adequate energy from a wide range of commonly available foods can meet the carbohydrate, protein, fat and micronutrient requirements of training and competition. (IOC, 2010, 1, emphasis added)

Meanwhile in the British National Health Service's (NHS) guidance on 'Food for Sport' (NHS, 2012), we are informed by a consultant sports nutritionist to the British Olympic Association that a "good diet", including carbohydrates which "are the fuel that power your exercise regime", can help athletes "get the best fitness and sport results". Similarly, the English Institute of Sport (EIS), which provides sports science support for elite athletes, notes that:

Optimal nutrition plays a pivotal role in supporting the training and competition demands of any elite athlete. Good food choices helps ensure fuel needs are met to promote adaption to training, to aid recovery in order to continue intensity training and to ensure good health to prevent illness and injury. (EIS, no date, emphasis added)

\section{The Influence of the 'Sportsnet'}


Coaches' understandings of the importance of physical preparation discourses, including those around 'optimal' nutrition for athletes, is pertinent given the influence they have over the training environment and the athletes with whom they work. Coaches influence the social context that athletes inhabit, which Howe (2004) refers to as the 'sportsnet', and therefore have the potential to shape athletes' identities and the culturally valued norms within their club (Howe, 2004; Jones, Glintmeyer and McKenzie, 2005; Sparkes and Smith, 2002). Therefore if coaches internalize contemporary understandings of 'optimal' nutrition as central to athletic performance, this is likely become culturally valued within that environment and impact on athletes' understandings of what it means to be an athlete (Jones, Glintmeyer and McKenzie, 2005). Coaches have been found to use a range of disciplinary techniques (Foucault, 1977) to encourage athletes to comply with their understandings of the 'best' way to physically prepare, including controlling athletes' lifestyles as well as, particularly at an elite level, monitoring athlete's weight and nutritional intake (Lang, 2010; McMahon and Dinan-Thompson, 2008; McMahon and Penney, 2013; Yorganci, 1993). In this sense, coaches and other adult stakeholders have been identified as contributing to "the legitimization and normalization of regulatory practices within the culture and critically, the adoption and expression of those practices in the swimmers' lives" (McMahon and Penney, 2013, 164). In swimming, Jones, Glintmeyer and McKenzie (2005) demonstrate how this culture of regulation contributed to one athlete developing an eating disorder, while McMahon and Penney (2013) highlight how coaches' beliefs about appropriate diet in Australian elite and sub-elite swimming, and athletes' desires to achieve a body that would be accepted by them, led swimmers to adopt pathogenic weight control behaviours both while they were active participants in the sport and long after their retirement from it.

This perhaps goes some way to explaining why athletes have been identified as being at higher risk of developing disordered eating than non-athletes (Hagmar et al., 2008; SundgotBorgen and Torstveit, 2004). Indeed, studies have shown that athletes who experience critical comments about their weight, instructions to lose weight or - critically in relation to this paper who experience pressure to restrict their diet are even more likely to engage with disordered eating practices (Bratland-Sanda and Sundgot-Borgen, 2013; Kerr, Berman and De Souza, 2006; Muscat and Long, 2008). Furthermore, athletes in early specialization sports - that is, sports where starting sport-specific training by ages 5 to 7 is considered necessary for future excellence (Balyi et al., 2005), such as swimming - have also been found to be at increased risk of developing eating disorders (Byrne and McLean, 2002).

\section{Deconstructing Sports Practice}

There is no consensus among sport nutritionists on optimal dietary requirements for athletes, however, in part because there are so many variables due to sport type, gender, age, growth rate and stage of physical maturity etc. (Heaney et al., 2011; Purcell, 2013). Scholars from the social science of sport also critique the traditional mechanistic view of athletes and their physical preparation as "values packaged in a scientific wrapping" (Vertinsky, 1985, 73). In particular, they note how guidelines on nutritional intake and weight management techniques for athletes pay little attention to the personal circumstance and context of athletes (Jones, Glintmeyer and McKenzie, 2005). In addition, this understanding of the 'best' way to physically prepare athletes objectifies them, rendering athletes and their bodies passive, purely rational, biological machine-like objects that can be "unproblematically trained, manipulated and measured" (Jones, Glintmeyer and McKenzie, 2005, 378). This regime positions athletes as "biophysical object[s] whose functions can be maximized by instrumental programmes of training and diet" (Pronger, 2002, xiii) and, in doing so, fails to recognize athletes as individual subjects capable of making decisions about their own bodies and bodily practices (Cassidy, Jones and Potrac, 2009; Jones, Glintmeyer and McKenzie, 2005). 
Scholars have also noted how common coaching practices, underpinned by understandings of coaches as 'experts' and athletes as 'novice recipients of this authoritative expertise' (Johns and Johns 2000, 231), encourage athletes to conform to normative behaviours in sport, leading them to submit to intensive and sometimes dangerous behaviours (Barker-Ruchti and Tinning, 2010; Johns and Johns, 2000; Lang, 2010). Considered in this light, it is perhaps unsurprising that athletes develop such behaviours as they actions are "congruent with their expected role and developing athletic identity" (Jones, Glintmeyer and McKenzie, 2005, 378), an example of adherence to the 'positive deviance' that Hughes and Coakley $(1991,308)$ identified more than two decades ago. Crucially, the discourses of physical preparation that pervade modern sport further encourage such conformity to this 'sports ethic' (Hughes and Coakley, 1991), positing that to be a well-prepared athlete who takes their identity as an athlete seriously, one must comply with strict training regimes and controlled lifestyles to achieve success (Lang, 2010; Potrac et al., 2000), such as following 'optimal' nutrition guidelines. This is not to suggest that an athlete's diet or weight have no bearing on their athletic practice. Rather, while coaching discourse emphasizes the rationalistic concepts of productivity and efficiency as central to athletic success (Cassidy, Jones and Potrac, 2009), other forms of knowledge regarding athletes' training and bodily practices are obscured.

\section{The Study}

This paper reports the findings from an ethnographic study into coaches' understanding of good practice when working with competitive youth swimmers and how they enact this in their practice. One of the key findings from the study was that coaches considered it good practice to educate youth athletes about what they referred to as 'good' or 'optimal' nutrition and consequently, particularly among coaches at the elite end of the performance spectrum, they enforced strict dietary rules, in some cases attempting to control athletes' lifestyles way beyond the swimming pool to achieve this. Other key findings from the study have been reported elsewhere (see Lang, 2010, 2014; Lang and Light, 2010), but only data relating to coaches' views on discourses of nutrition and that has not previously been published is used here.

An ethnographic approach was adopted to enable a thorough exploration of the discursive resources that coaches had access to and were shaped by (Hammersley and Atkinson, 1995). Indeed, ethnography was employed in this study because it is:

... concerned with what people are, how they behave, how they interact together. It aims to uncover their beliefs, values, perspectives, motivations and how all these things develop or change over time or from situation to situation. It tries to do all this from within the group, and from within the perspectives of the group's members. (Woods, 1991, 4; original emphasis)

Data was generated through participant observations of 13 coaches at three ASA-affiliated clubs in north England to triangulate data collection by working in different settings (Lincoln and Guba, 1985). The clubs were placed at different levels of the elite-development ladder and categorized as elite, sub-elite or low level according to their position in the National Swimming League competition, England's largest interclub swimming event (National Swimming League, 2013). All coaches were observed during training sessions over a 12-month period. Participants were between 22- and 60-years-old and four were women. Table 1 outlines the clubs and poolside staff that participated. Pseudonyms have been used throughout.

Data were generated via written and verbally recorded field 'notes' that documented both observed behaviour and information gathered during informal discussions. Observations took place in blocks of several hours, beginning shortly before training began and running until after sessions had ended to allow observation of athletes' and coaches' interactions on the poolside. 
Most observations were of pool sessions, although gym-based training and competitions also were observed at two clubs.

Table 1.1: Clubs and participants in observations and interviews

\begin{tabular}{|l|l|l|l|}
\hline & $\begin{array}{l}\text { Elite Club Central } \\
\text { Seals }\end{array}$ & $\begin{array}{l}\text { Sub-elite Club North } \\
\text { Eels }\end{array}$ & $\begin{array}{l}\text { Low-level Club South } \\
\text { Dolphins }\end{array}$ \\
\hline Participating Coaches & Andrew & Amanda & Jim \\
& Steven & Keith & \\
& John & Dave \\
& Mike & Frank* & \\
& Chris & Helen* & \\
\hline & Jenny & & \\
\hline
\end{tabular}

* Coaches who did not take part in interviews.

The head coaches of three ASA-affiliated swimming clubs were approached first to discuss access. The club chair gave overall approval for the author to work within each club and once the head coach's consent had been negotiated, assistant coaches and poolside helpers were approached to take part. Letters informing athletes and their parents about the research were posted on club notice boards and the researcher was introduced to swimmers and parents before the field work. Observations lasted between seven and nine weeks at each club, until sufficient data had been gathered to inform the interview questions and 'theoretical saturation' (Glaser and Strauss, 1967) had been reached. Most observations were of pool sessions, although land-based training and competitions also were observed if scheduled. All six coaches at the elite club Central Seals were observed, plus five coaches at sub-elite club North Eels and two at 'low-level' club South Dolphins.

Observations were followed by semi-structured interviews with coaches. Eleven of the 13 coaches involved in observations were interviewed; one declined and one left the club during the fieldwork. Interviews drew on observational data and informal discussions with coaches and past literature. The questions sought the perspective of coaching staff regards the club and squad structure, the role of the coach, notions of best practice in athlete development, and child protection issues, among others. Interviews were semi-structured and lasted between 50 minutes and two hours and were recorded with the permission of the coaches. The findings presented here draw on both observational and interview data. The research was approved by the author's institutional research ethics committee and, as part of this, at all stages of the data-generation process, efforts were made to maintain participants' anonymity.

\section{Data Analysis}

Data analysis was ongoing and began during the observations. All field notes - verbal 'notes' recorded during observations and expanded upon after each session - and interview transcripts were typed up and interviews transcribed before being subject to inductive analysis to allow findings to emerge from the dominant themes inherent in them (Goetz and LeCompte, 1984). This involved reading and re-reading the text and unpacking relevant patterns, themes, and interrelationships (Johnson and Christensen, 2012). Simultaneously, segments of text were coded into emergent themes, which were repeatedly examined for similarities, differences and patterns. To help explain the themes arising, analytical memos were also used to note "preliminary and tentative connections to various theoretical concepts" (Sparkes and Smith, 2014, 18). Through this process themes became increasingly refined, finally resulting in themes discussed in this paper. 
Finally, anonymized transcripts and analytical interpretations of these were sent to participants as part of the process of establishing trustworthiness and to encourage reflexive elaboration (Sparkes, 1989).

\section{Findings and Discussion}

In line with the dominance of the performance discourse, and in particular of physical preparation discourses of 'optimal' nutrition and weight management, coaches across all levels of the performance spectrum accepted the role played by the sports science sub-discipline of nutrition in physically preparing athletes:

Nutrition's pretty important you know. I don't know a lot on nutrition but I think it's vital they have the right sort of food though ... it helps them prepare. (John, elite club)

Swimmers must be very professional in terms of just being prepared for everything, being first on poolside and being there early, looking after yourself in terms of going to bed early etc., eating properly. (Frank, sub-elite club)

These extracts illustrate the pervasiveness of the dominant discursive regime that underpins competitive sport - performance rather than participation (Tinning, 1997). This in turn influences what these coaches know and simultaneously obscures other forms of knowledge, guiding the way these coaches understand what is true and how they behave, in this case leading them to uncritically accept the role of 'optimal' nutrition as a crucial part of an athlete's physical preparation.

Coaches at the elite club drew on an "engineering input-output model" of food as fuel (Spoel, Harris and Henwood, 2012, 4) to explain why nutrition was important for athletes:

What you put into your body is going to have an effect on what it can do. If we don't put the right fuel in we're not going to get a good performance. (Chris, elite club)

Good nutrition has got to be one of the most important things because without food you've got no fuel. (Mike, elite club)

Nutrition plays a massive role I think. It helps them to go through growth spurts, it helps them to grow, it helps them to fuel their body properly. I always tell it like Michael Schumacher wouldn't go to your normal Shell garage and put just your normal leaded petrol in his tank and that's the same for these guys ... it's got to be the right food, good carbs, low fat, you know. (Steven, elite club)

As the final quote from Steven indicates, a hierarchy of 'good' versus 'bad' foods was also evident in discussions, especially among coaches from the elite club:

... with the little ones and they go to mini galas which is a big thing for them to do a competition and the amount of times they sit on the side eating a packet of crisps, chocolate and they're about to get in the pool five minutes later, no ... we try and educate them as much as we can, tell them about good food and the wrong kinds of food, to bring some pasta, jacket potatoes is another good one, jelly, a bit of fruit. (Jenny, elite club)

If you have a kid who's drinking Coca-Cola and eating sweets every day they're gonna struggle. I had a swimmer like that who was coming here [to the pool] eating a bag of sweets a day and he'd last about half an hour. It's so important that they have the right food. (John, elite club) 
These coaches considered 'optimal' nutrition central to ensuring athletic success in swimming, and to explain this coaches, especially those at the elite end of the performance spectrum, drew on the culturally prevalent rationalistic metaphor of food as fuel. Within this, not all food was considered equal - after all, as the analogy goes high-performance cars need highquality, high-octane fuel if they are to perform well. Rather, a qualitative hierarchy of foods was evident, some considered 'good' and some 'bad' (Spoel, Harris and Henwood, 2012). In other words, while food is essential to fuel athletes, any old food will not do; it must be 'nutrient rich', 'good' food. Just as the NHS (2012) refers to a "good diet" and the EIS (no date) to "good food", so the coaches in this study identified a hierarchy of food, with some foods celebrated as 'good', such as carbohydrate-rich pasta and unprocessed foods like fruit, and some demonized as 'bad' or "worse than valueless empty fill; it is positively harmful, a dangerous body pollutant" (Spoel, Harris and Henwood, 2012, 5), such as high-fat and processed goods like crisps and sweets.

A consequence of this conceptualization is that food becomes reduced to its calorific components - what McMahon and Penney (2013) calls its 'fat number' - with food understood as necessary only to provide the body with sufficient energy to train or compete, and eating reduced to a functional, utilitarian act with no inherent pleasure. Kaye-Rasnake et al. $(2005,277)$ argue that positioning certain foods as inherently 'good' and others as inherently 'bad' is unhelpful and potentially dangerous as "all foods must be considered in relation to other foods and a complete diet". Jones, Glintmeyer and McKenzie (2005) and McMahon and Penney (2013) highlight the potential consequences of this way of conceptualizing food, suggesting that 'fat numbers' and monitoring calorific intake come to govern and regulate athletes' lives physically and emotionally both during their career in sport and long after it has ended and can cause athletes to develop unhealthy eating practices.

The functionalist food-as-fuel metaphor also (re)produces reductionist and mechanistic understandings of the athletic body as a machine (Cassidy, Jones and Potrac, 2009; Jones, Glintmeyer and McKenzie, 2005; Pronger, 2002; Tinning, 1997) and simplistically implies that success can be achieved by any athlete who is willing to train hard enough or, in this case, eat the 'right' food. Inherent in this is that the responsibility for failure to perform is assumed to lie with the athlete themselves, the result of an athlete's failure to prepare or train correctly, perhaps for example, by failing to follow 'optimal' nutritional guidelines. This idea was echoed by several coaches, mainly but not exclusively at the elite club:

Frank explains to the swimmers that he's there to ensure they 'achieve the best they can'. He says this means training hard, as often as possible 'rather than going out with their mates,' and means making 'good food choices instead of bloody McDonalds.' All this, he says, shows the swimmers are committed to the sport, 'doing what you can to be the best you can' and that if they aren't going to do these things they aren't helping themselves achieve this. (fieldnotes, sub-elite club)

... they've got to be hard working, you know, because any swimmer that doesn't want to train hard, eat right - make it their life really - they probably won't succeed because they're just not committed enough and I can't do anything with that ... it' comes down to them and how much they want it (Mike, elite club)

As these statements suggest, then, athletes who are 'serious' about their performance should ensure they 'eat smart' and 'eat right'. The concomitant suggestion is that athletes who fail to follow this advice are, presumably, not 'serious' about their performance or about their identity as an athlete. Indeed, coaches constructed athletes who did not adhere to dominant ideas about the 'best' way to physically prepare as uncommitted to their sport, lazy and not 'proper' athletes. 
At the elite club, coaches' beliefs in the importance of 'optimal' nutrition for athletic preparation led them to enforce strict nutritional guidelines in an attempt to control athletes' diet in and beyond the pool, including banning certain foods and removing any 'contraband':

Field notes, 4/05/07: Steven [elite club] explained that he has banned his athletes from eating crisps, chocolate and other 'junk' food at the pool and at home. He said that when he first came to coach at the club, 'some of the kids were a bit podgy so I banned all junk food and told them that if I saw them with any, I'd take it off them for myself.' $\mathrm{He}$ explained how the next day a young male swimmer from his squad came onto the poolside munching on a chocolate bar so he took it off him and ate it himself. Steven told me that the child's parents were furious and eventually left the club. Steven said it was a shame because the kid was one of the club's better swimmers but added that, 'you've got to be firm. Andrew [assistant coach] stood by me. Now none of the kids are allowed to eat junk at the pool'.

Meanwhile, coaches at the non-elite clubs but adopted a more relaxed stance to athlete nutrition:

I'm sure nutrition is very important (laughs) but ... it's Sunday today, isn't it? Well, Saturday night and Sunday night at eight o' clock, quarter past eight, at the chip shop down the road, there's a queue a mile long (laughs)! I think it's the general treat after training. There's nothing wrong with it, it's just a treat and it's not going to do them any harm. (Keith, sub-elite club)

... my personal thought is that everything's good in moderation. ... I mean we can advise them on it and ... it is important what they eat but I wouldn't say to them, you know, cut everything out ... it's not the be all and end all. (Kevin, low-level club)

Only Kevin, from the 'low-level' club, questioned the seemingly 'natural' link made within discourses of physical preparation between athlete nutrition and performance and expressed an awareness of the potential dangers of enforcing nutritional rules:

You have to be careful talking to them about diet 'cos they can be very sensitive about their weight ... Some of the girls, particularly the older girls that used to be in my group, I see them and I think to myself they seem to have lost a lot of weight, you know because they've grown up, but I wouldn't say that to them, you know, they're kids, at that age where their bodies do change, don't they? And I don't think it's my position to say anything, you know, you should be eating this or that, watch your weight and what you eat ... whatever because, it's natural anyway to change shape and it can make them sensitive ... erm, and I guess I mean, erm, it's not as, as erm simple as eating X equals good performance anyway I don't think, you know, and it can make them sensitive about their weight, which can, you know, erm, it can cause problems ... like about what they eat, you know.

Although coaches at the non-elite level clubs showed an awareness of discourses of physical preparation and optimal nutrition, they were also critical of it, perhaps because at the lower echelons of swimming the performance discourse gives way to a more participatory understanding of sport that stresses "inclusion, equity, involvement, enjoyment, social justice, caring, cooperation, movement" (Tinning, 1997, 97-8; see also Lang, 2010). However, Kevin was the only coach to express an awareness of the potential dangers of focusing on athletes' diet, particularly among young athletes whose bodies are still developing (Kerr, Berman and De Souza, 2006; Muscat and Long, 2008). In doing so Kevin also rejected dominant understandings that construct 
athletes as biophysical objects who can be "unproblematically trained, manipulated and measured" (Jones, Glintmeyer and McKenzie, 2005, 378). Rather, Kevin recognized the athletes he worked with as individuals with their own personal circumstances and contexts (Jones, Glintmeyer and McKenzie, 2005), first and foremost children who were in constant physical and perpetual development.

\section{Conclusion}

This paper has explored how coaches understand and enact knowledge of athlete preparation in relation to 'optimal' nutrition in their practice when working with competitive youth swimmers. Legitimized through dominant bio-scientific discourses of performance and the 'best' way to physically prepare athletes, all coaches highlighted the importance of 'optimal' nutrition for athletes. However, the data revealed clear differences between coaches at the three clubs, most notably between coaches at the elite club and those at the two non-elite clubs. Coaches at the elite club enforced strict dietary rules within and beyond the swimming pool and punished athletes for failing to follow these, despite disagreement from some parents that resulted in athletes leaving the club. Coaches at the elite club were also more likely to draw on an "engineering input-output model" of food as fuel (Spoel, Harris and Henwood, 2012, 4) and, in doing so, reduce food to its nutritional content and construct the athletic body as a machine (Cassidy, Jones and Potrac, 2009; Jones, Glintmeyer and McKenzie, 2005; Pronger, 2002; Tinning, 1997). Meanwhile, coaches at the two non-elite clubs tended to adopt a more relaxed stance and, in some cases, recognized that focusing on athletes' diet, particularly among young athletes, could result in athletes developing unhealthy eating practices and negative body image. It appears, then, that the performance level at which coaches worked mediated the discourses that underpinned their knowledge, with coaches at the elite club subscribing more to a discourse of performance, which "implicitly support[s] competition, survival of the fittest, and the exclusion of the less fit or able" (Tinning, 1997, 9798), while those at the two non-elite clubs aligned with a participation discourse that stresses involvement and enjoyment (Tinning, 1997).

The consequences of the findings presented here are manifold. Firstly, in promoting only one seemingly 'correct' way of preparing as a swimmer - in the case discussed here, following 'optimal' nutrition guidelines - the coaches at the elite club created an exclusionary 'sportsnet' (Rowe, 2004) whereby athletes who were unwilling or unable to conform to their coaches' expectations were at best, marginalized - for example, written off as lacking ambition and commitment - and, at worst, excluded entirely - for example, by being channeled out of competitive youth swimming, as occurred in at least one instance when an athlete left the club following disagreement with the coach about the club's strict ban on certain foods.

In addition, enforcing rules to encourage athlete conformity to coaches' understandings of appropriate athlete nutrition restricts athletes' autonomy, positioning them as incapable of making decisions about their own bodies and bodily practices, further legitimizing the subjectivity of the unquestioning, compliant and dependent athlete (Cassidy, Jones and Potrac, 2009; Johns and Johns, 2000; Jones, Glintmeyer and McKenzie, 2005). This disempowers athletes and, worryingly, can facilitate abuse and harassment (Brackenridge et al., 2010; Klein and Palzkill, 1998; Lang, $2010 \mathrm{~b}$ ). It also fails to take into consideration the personal circumstances and context of athletes (Jones, Glintmeyer and McKenzie, 2005) and places them at risk of developing disordered eating practices (Kerr, Berman and De Souza, 2006; Muscat and Long, 2008).

Moreover in banning certain foods, coaches are positioning some foods as inherently 'good' and others as inherently 'bad' - a construction that is unhelpful and potentially dangerous as it fails to acknowledge the importance of balance and that "some 'bad foods' may actually contain 
essential nutrients and be important components of a balanced diet" (Kaye-Rasnake et al., 2005, 286). It has even been suggested that positioning certain foods in this way can lead to disordered eating practices and a condition known as orthorexia nervosa, in which suffers obsess about eating foods perceived to be 'good' and whose consequences can be as severe as those of anorexia nervosa (Bratman, 2000). This concern is particularly salient in light of understandings of the 'sports ethics (Hughes and Coakley, 1991, 308) discussed earlier, and how athletes' 'positive deviance' can place them at greater risk of developing disordered eating than non-athletes (Bratland-Sanda and Sundgot-Borgen, 2013; Hagmar et al., 2008; Sundgot-Borgen and Torstveit, 2004).

As key individuals 'with clear, recognized legal, professional-ethical and/or cultural responsibility for the safety, health, development and wellbeing of the child' (Committee on the Rights of the Child, 2011: para. 33), coaches have a legal as well as a moral responsibility to protect children from harm and to put what is best for children at the heart of everything they do. The findings presented here raise important questions about the extent to which all coaches, but particularly those at the elite end of the spectrum where performance often takes precedence over participation and enjoyment (Tinning, 1997), are meeting these requirements, and suggest everyone involved in sport needs to more carefully consider the (perhaps unintended) consequences of traditional rationalistic understandings of athletes and their physical preparation.

\section{Acknowledgements}

The author would like to thank the editor and the anonymous reviewers for their constructive comments on an earlier version of this paper. 


\section{REFERENCES}

Amateur Swimming Association. 2012b. ASA Level 3 Certificate in Coaching Swimming (QCF). Available: http://www.swimming.org/assets/uploads/library/Qualification_Spec__L3CS_-_RW_Signed_Off.pdf (accessed 27 January 2014).

Amateur Swimming Association. 2013. ASA Level 2 Certificate in Coaching Swimming (QCF). Available: http://www.swimming.org/assets/uploads/library/L2_CS__Qualification_Specification_for_Centres.pdf (accessed 27 January 2014).

Anderson, Carlin M., Petrie, Tyler A., and Neumann, Craig S. 2011. "Psychosocial Correlates of Bulimic Symptoms Among NCAA Division-I Female Collegiate Gymnasts and Swimmers/Divers." Journal of Sport and Exercise Psychology 33: 483-505.

Barker-Ruchti, Nathalie \& Tinning, Richard. 2010. "Foucault in Leotards: Corporeal Discipline in Women's Artistic Gymnastics." Sociology of Sport Journal 27: 229-50.

Balyi, Istvan, Cardinal, Charles, Higgs, Colin, Norris, Steve \& Way, Richard. 2005. Canadian Sport for Life: Long Term Athlete Development. Vancouver, BC.: Canadian Sports Centers.

Bonci, Christine M., Bonci, Leslie J., Granger, Lorita R., Johnson, Craig L., Malina, Robert. M., Milne, Leslie W., Ryan, Randa R. \& Vanderbunt, Erin M. 2008 "National Athletic Trainers' Association Position Statement: Preventing, Detecting and Managing Disordered Eating in Athletes." Journal of Athletic Training 43: 80-108.

Brackenridge, Celia H., Fasting, Kari, Kirby, Sandra and Leahy, Trish. 2010. Protecting Children from Violence in Sport: A Review with a Focus on Industrialized Countries. Florence: UNICEF Innocenti Research Center.

Bratland-Sanda, Solfrid and Sundgot-Borgen, Jorunn. 2013. "Eating Disorders in Athletes: Overview of Prevalence, Risk Factors and Recommendations for Prevention and Treatment." European Journal of Sport Science 13: 499-508.

Bratman, Steven. 2000. Health Food Junkies: Overcoming the Obsession with Healthful Eating. New York: Broadway Books.

Bridel, William. 2013. "Not Fat, Not Skinny, Functional Enough to Finish: Interrogating Constructions of Health in the Ironman Triathlon." Leisure/Loisir 37: 37-56.

Byrne, Susan \& McLean, N. 2002. "Elite Athletes: Effects of the Pressure to Be Thin." Journal of Science and Medicine in Sport 5: 80-94.

Cassidy, Tanya, Jones, Robyn .L and Potrac, Paul. 2009. Understanding Sports Coaching: The Social, Cultural and Pedagogical Foundations of Coaching Practice. $\left(2^{\text {nd }}\right.$ ed.). London: Routledge.

Coakley, Jay. 1992. "Burnout among Adolescent Athletes: A Personal Failure or a Social Problem?" Sociology of Sport Journal. 9: 271-85.

Dunford, Marie. 2010. Fundamentals of Sport and Exercise Nutrition. Leeds: Human Kinetics.

English Institute of Sport. No Date. Performance Nutrition. Available: http://www.eis2win.co.uk/pages/EIS_Expertise.aspx (accessed 22/3/14).

Foucault, Michel. 1977. Discipline and Punish: The Birth of the Prison. London: Allen Lane.

Gibson, Jennifer C., Stuart-Hill, Lynneth, Martin, Steven \& Gaul, Catherine. 2011. "Nutrition of Junior Canadian Female Soccer Athletes." International Journal of Sport Nutrition and Exercise Metabolism 21: 507-14.

Glaser, Barney L. and Strauss, Anselm G. 1967. The Discovery of Grounded Theory: A Strategy for Qualitative Research. Chicago: Aldine.

Goertz, Judith and LeCompte, Margaret. 1984. Ethnography and Qualitative Design in Educational Research. New York: Academic Press.

Hagmar, Magnus, Hirschberg A L., Berglund L. \& Berglund B. 2008. "Special Attention to the Weight-Control Strategies Employed by Olympic Athletes Striving for Leanness is Required." Clinical Journal of Sports Medicine 18:5-9. 
Hammersley, Martyn and Atkinson, Paul. 1995. Ethnography: Principles in Practice. (2 ${ }^{\text {nd }}$ ed.). London: Routledge.

Heaney, Susan, O’Connor, Helen, Naughton, Geraldine and Gifford, Janelle. 2008. "Towards an Understanding of the Barriers to Good Nutrition for Elite Athletes." International Journal of Sports Science and Coaching 3: 391-401.

Howe, David. 2004. Sport, Professionalism and Pain: Ethnographies of Injury and Risk. London: Routledge.

Hughes, Richard and Coakley, Jay J. 1991. "Positive Deviance among Athletes: The Implications of Over Conformity to the Sport Ethic." Sociology of Sport Journal 8: 307-25.

International Olympic Committee Medical Commission. 2006. Position Stand on the Female Athlete Triad. Available:

http://www.olympic.org/documents/reports/en/en_report_917.pdf (accessed 28/05/14).

International Olympic Committee. 2010. Consensus Statement on Sports Nutrition. Available: http://www.olympic.org/Documents/Reports/EN/CONSENSUS-FINAL-v8-en.pdf (accessed 22/3/14).

International Olympic Committee. 2012. Nutrition for Athletes: A Practical Guide to Eating for Health and Performance, Prepared by the Nutrition Working Group of the International Olympic Committee. Available:

http://www.olympic.org/documents/reports/en/en_report_833.pdf (accessed 25/05/14).

Johnson, Burke and Christensen, Larry B. 2012. Educational Research: Quantitative, Qualitative, and Mixed Approaches. London: Sage.

Johns, David P. \& Johns, Jennifer S. 2000. "Surveillance, Subjectivism and Technologies of Power: An Analysis of the Discursive Practice of High-Performance Sport." International Review for the Sociology of Sport 35: 219-34.

Jones, Robyn L., Glintmeyer, Nikki and McKenzie, Alex. 2005. "Slim Bodies, Eating Disorders and the Coach-Athlete Relationship: A Tale of Identity Creation and Disruption." International Review for the Sociology of Sport 40: 377-91.

Kaye-Rasnake, L., Laube, Emily, Lewis, Meghan and Linscheid, Thomas R. 2005. "Children's Nutritional Judgments: Relation to Eating Attitudes and Body Image." Health Communication 18: 275-89.

Kerr, Gretchen, Berman, Erica \& De Souza' Mary J. 2006. "Disordered Eating in Women's Gymnastics: Perspectives of Athletes, Coaches, Parents, and Judges.” Journal of Applied Sport Psychology 18: 28-43.

Klein, Michael and Palzkill, Birgit. 1998. Violence against Girls and Women in Sport.

Dusseldorf: Ministry of Women, Youth, Family and Health: North Rhine-Westphalia.

Lang, Melanie. 2010. "Surveillance and Conformity in Competitive Youth Swimming." Sport, Education and Society 15: 19-37.

Lang, Melanie. 2014. "Touchy Subject: A Foucauldian Analysis of Coaches' Perceptions of Adult-Child Touch in Youth Swimming." Sociology of Sport Journal.

Lang, Melanie and Light, Richard. 2010. "Interpreting and Implementing the Long Term Athlete

Development Model: English Swimming Coaches' Views on the (Swimming) LTAD in

Practice." International Journal of Sports Science and Coaching 5: 389-402.

Lee, Jessica and McDonald, Doune. 2010. “'Are They Just Checking Our Obesity or What?' The Healthism Discourse and Rural Young Women." Sport, Education and Society 15: 20319.

Lincoln, Yvonna S. and Guba, Egon G. 1985. Naturalistic Inquiry. Newbury Park, CA: Sage.

McArdle William D., Katch Frank I. and Katch, Victor, L. 2009. Sports and Exercise Nutrition $\left(3^{\text {rd }}\right.$ ed). Baltimore, MD: Lippincott Williams \& Wilkins.

McMahon, Jennifer A. and Dinan-Thompson, Maree. 2008. "A Malleable Body: Revelations from an Elite Australian Swimmer.” ACHPER Healthy Lifestyles Journal 55: 23-8. 
McMahon, Jennifer A. and Penney, Dawn. 2013. "(Self-) Surveillance and (Self-) Regulation: Living by Fat Numbers within and Beyond a Sporting Culture." Qualitative Research in Sport, Exercise and Health 5: 157-78.

McMahon, Jennifer A. and Penney, Dawn. 2013: "Body Pedagogies, Coaching and Culture: Three Australian Swimmers' Lived Experiences.” Physical Education and Sport Pedagogy 18: 317-35.

Meyer, Flavia, O’Connor, Helen and Shirreffs, Susan M. 2007. "International Association of Athletics Federations: Nutrition for the Young Athlete." Journal of Sports Science 25 (Supplement 1): S73-S82.

Muscat, Anne C. and Long, Bonita C. 2008. "Critical Comments About Body Shape and Weight: Disordered Eating of Female Athletes and Sport Participants." Journal of Applied Sport Psychology 20: 1-24.

National Athletic Trainers' Association. 2014. About NATA. Available: http://www.nata.org/aboutNATA (accessed 02/05/14).

National Health Service (2012) Food for Sport. Online. Available: http://www.nhs.uk/Livewell/Goodfood/Pages/Sport.aspx (accessed 22/3/14).

National Swimming League. 2013. The National Swimming League. Available: http://www.nationalswimmingleague.org.uk (accessed 15/05/14).

Nattiv, Aurelia, Loucks, Anne B. \& Manore Melinda M. 2007. "The Female Athlete Triad." Medicine and Science in Sports and Exercise 39: 1867-82.

Potrac, Paul, Brewer, Clive, Jones, Robyn L., Armour, Kathy \& Hoff, Jan. 2000. "Towards an Holistic Understanding of the Coaching Process." Quest 52: 186-99.

Pronger, Brian. 2002. Body Facism: Salvation in the Technology of Physical Fitness. Toronto: University of Toronto Press.

Purcell, Laura K. 2013. "Sport Nutrition for Young Athletes.” Paediatric Child Health 18: 2002.

Rodriguez, Nancy, DiMarco, Nancy and Langley, Susie. 2001. Position Stand: Nutrition and Athletic Performance. Available: http://www.ncbi.nlm.nih.gov/pubmed/19225360 (accessed 02/05/14).

Romana, Venkata Y. 2010. “Energy Requirements of Indian Athletes in Various Sports.” British Journal of Sports Medicine 44: 40-50.

Sparkes, Andrew. 1989. "Paradigmatic Confusions and the Evasions of Critical Issues in Naturalistic Research. "Journal of Teaching in Physical Education 8: 131-51.

Sparkes, Andew C. and Smith, Brett. 2002. "Sport, Spinal Cord Injury, Embodied Masculinities, and the Dilemmas of Narrative Identity." Men and Masculinities 4: 258-85.

Sparkes, Andrew, C. and Smith, Brett. 2014. Qualitative Research Methods in Sport, Exercise and Health: From Process to Product. London: Routledge.

Spoel, Philippa, Harris, Roma \& Henwood, Flis. 2012. "Healthy Living: Metaphors We Eat By?" Present Tense: A Journal of Rhetoric in Society 2: 1-11.

Sundgot-Borgen, Jorunn and Torstveit, Monica K. 2004. "Prevalence of Eating Disorders in Elite Athletes is Higher Than in the General Population." Clinical Journal of Sport Medicine 14: 25-32.

Tinning, Richard. 1997. "Performance and Participation Discourses in Human Movement: Toward a Socially Critical Physical Education.” In: Fernández-Balboa, Juan-Miguel. (ed.) Critical Postmodernism in Human Movement, Physical Education and Sport. Albany, NY.: State University of New York Press. (99-119).

US Anti-Doping Agency. 2010. Optimal Dietary Intake: The Basics. Available: http://www.usada.org/files/active/athletes/NutritionBookletFinal.pdf (accessed 28/05/14).

Vertinsky, Patricia. 1985. "Risk Benefit Analysis of Health Promotions: Opportunities and Threats for Physical Education.” Quest 37: 71-83. 
Woods, Peter. 1991. Inside Schools: Ethnography in Educational Research. London: Routledge. Yorganci, Ilkay. 1993. "Preliminary Findings from a Survey of Gender Relationships and Sexual Harassment in Sport.” In: Brackenridge, C. (ed.). Body Matters: Leisure Images and Lifestyles. Brighton: Leisure Studies Association.

\section{ABOUT THE AUTHOR}

Dr. Melanie Lang: Melanie is a sociologist and former British international youth swimmer, swimming coach and journalist who now works at Edge Hill University. Her research centres on the policy and practice of safeguarding and child protection in sport and children's rights and empowerment in sport. She is co-editor of the book 'Safeguarding, Child Protection and Abuse in Sport: International Perspectives in Research, Policy and Practice' and sits on the NSPCC Child Protection in Sport Unit Research Evidence Advisory Group and the editorial board of the Irish Journal of Sociology. 